\title{
A OLIMPÍADA BRASILEIRA DE FÍSICA NO ESTADO DE SÃO PAULO E A DIFUSÃO DO CONHECIMENTO NA UNIVERSIDADE DE SÃO PAULO
}

\author{
Ricardo Gomes Pereira*, Euclydes Marega Jr.*
}

\section{RESUMO}

Olimpíadas do conhecimento, tais como a Olimpíada Brasileira de Física, Matemática, Química, Astronomia e Biologia, financiadas por órgãos do governo brasileiro, vêm sendo utilizadas ao longo dos últimos anos como instrumento de divulgação e estimulo ao estudo de ciências e matemática para jovens do ensino médio e fundamental.

Desde 2006, o Instituto de Física de São Carlos promove, junto com as atividades regulares da Olimpíada Brasileira de Física no estado de São Paulo, atividades paralelas com o objetivo de divulgar o conhecimento produzido na Universidade para alunos, professores e comunidade em geral. Os resultados obtidos são apresentados e analisados ao longo deste artigo.

Palavras-chave: Física. Olimpíada do Conhecimento. Difusão do conhecimento.

\section{ABSTRACT}

Science competitions, such as the Brazilians Physic, Mathematical, Chemical, Astronomy and Biology Olympiads, are becoming popular and every year thousands of students from basic to high schools are attracted to participate motivated by the challenges. These competitions are becoming powerful criteria to evaluate the education system as well.

Since 2006 the Instituto de Física de São Carlos is the institution that coordinates the Brazilian Physics Olympiad (OBF) at São Paulo state. Parallel with the regular calendar of the OBF, activities such as: visits, courses, seminars were happens and opened to all community. In this paper we analyze the results of these activities as a way to promote the knowledge dissemination produced in the University.

Key words: Physic. Science competition. Knowledge dissemination.

* Instituto de Física de São Carlos, Universidade de São Paulo, 13560-970, São Carlos, São Paulo, Brasil. 


\section{INTRODUÇÃO}

O governo brasileiro vem, nos últimos anos, estimulando ações que visam fortalecer e criar novos eventos que levem os alunos a ter maior interesse pelo conhecimento.

Este é o caso das Olimpíadas Brasileiras de Física, Matemática, Química, Astronomia e Biologia que recebem, anualmente, financiamento do Conselho Nacional de Desenvolvimento Científico. Mais recentemente o governo, através do Ministério da Educação, vem financiando a Olimpíada Brasileira de Matemática para escolas públicas, que atingiu no ano de 2008 um total de 18 milhões de alunos no território nacional.

Trata-se de eventos de âmbito nacional, nos quais estudantes do ensino médio e fundamental participam de uma série de atividades que têm como objetivo estimular o estudo de ciências e matemática. Uma das metas do novo Plano de Desenvolvimento da Educação é a criação de um evento similar na área de humanas, relacionado com o estudo da língua portuguesa.

Este tipo de competição, além de estimular o desenvolvimento de habilidades científicas e intelectuais, requer persistência, motivação e curiosidade, fatores determinantes para o desenvolvimento do aluno quanto indivíduo.

De acordo com Grote (1995) e Mann (1984) muitos educadores estimulam a participação dos alunos em atividades científicas extracurriculares, como em feiras e olimpíadas do conhecimento, como um caminho para os alunos desenvolverem suas habilidades e interesse pela ciência. A mesma opinião é seguida por Bellipanni e Lilly (1999) que afirmam "se os estudantes seguem uma metodologia científica no desenvolvimento de seus projetos e estudos, entenderão mais facilmente os conceitos científicos”. Estimular os estudantes a participarem de atividades científicas pode ser muito importante a longo prazo, principalmente para a escolha da carreira. Huler (1991) comprovou que os alunos participantes do Westinghouse Talent Search escolheram carreiras científicas como profissão e de acordo com Olson (1985), adultos que profissionalmente trabalham com ciências indicaram que o gosto pelo estudo, quando jovens, influenciou na escolha da carreira.

\section{MATERIAIS E MÉTODOS}

\section{A OLIMPÍADA BRASILEIRA DE FÍSICA}

Competições do conhecimento, tais como a Olimpíada de Física, vêm sendo utilizadas em vários países do mundo (cerca de noventa) como instrumento de divulgação de Física e também como forma de estimular jovens a seguir carreiras científico-tecnológicas. Considerando esses e outros aspectos, a Sociedade Brasileira de Física (SBF) realiza, desde 1999, a Olimpíada Brasileira de Física (http://www.sbf1.sbfisica.org.br/ olimpiadas/). Este é um programa permanente relativo, inicialmente, ao ensino médio e, em uma segunda etapa, também às últimas séries do ensino fundamental, como proposto pela Diretoria e aprovado, em março de 2001, pelo Conselho da Sociedade, como um dos eventos anuais patrocinados pela SBF.

A OBF é coordenada e organizada em nível nacional por uma comissão (a Comissão da Olimpíada Brasileira de Física - COBF) composta por Presidente, Vice-Presidente, Tesoureiro, Secretário e Secretário Executivo. Em cada estado onde ocorre a OBF há um coordenador, em geral, professor de universidade federal ou estadual. No ano de 2007 participaram do evento 27 estados e o distrito federal.

Os objetivos principais do Programa Olimpíada Brasileira de Física, aprovados pelo Conselho da SBF que, em sua reunião de março de 2001, efetivou o projeto e a Comissão da OBF, são:

a) despertar e estimular nos alunos do ensino médio e fundamental o interesse pela Física e pela ciência, em geral;

b) proporcionar desafios intelectuais de ordem científica aos estudantes;

c) identificar os estudantes talentosos em Física preparando-os para as Olimpíadas Internacionais e estimulando-os a seguir carreiras científico-tecnológicas;

d) motivar professores e estudantes para o estudo e aprendizagem da Física;

e) desenvolver nos estudantes habilidades exigidas para pesquisa na área de Física;

f) proporcionar atividades de atualização para professores com o desenvolvimento de novas tecnologias de ensino, bem como proporcionar o desenvolvimento de novas metodologias de ensino, tanto na área 
experimental, como na área de simulações e na análise e resolução de problemas;

(g) investigar e adquirir informações sobre os limites e possibilidades dos estudantes do ensino fundamental e médio com relação ao conhecimento nas respectivas faixas etárias e níveis de escolaridade;

(h) contribuir para a investigação do processo ensinoaprendizagem de Física;

(i) aproximar o pesquisador da Universidade dos professores e estudantes do ensino médio e fundamental;

(j) contribuir para a realização de diagnósticos dos currículos escolares do ensino médio e fundamental.

A Olimpíada Brasileira de Física (OBF) é realizada em três fases:

- A primeira fase é realizada na escola de cada estudante e dela podem participar todos os estudantes inscritos no ensino médio ou no último ano do ensino fundamental. A prova consiste de 20 questões de múltipla escolha.

- A segunda fase é realizada em locais determinados pelo Coordenador Estadual e dela participam os estudantes que atingem na primeira fase um número mínimo de acertos definido pela Comissão da OBF. A prova para os $1{ }^{\text {s }}$ e 2ํs anos do Ensino Médio consiste em 16 questões dissertativas, sendo que 0 aluno deverá escolher oito delas para resolver, devido a diferença na grade curricular nas diversas unidades na federação brasileira. Para os alunos dos últimos anos do Ensino Fundamental e Médio há oito questões dissertativas, devido o programa ser mais abrangente. A cada escola é dado o direito de inscrever três alunos em cada série mesmo se estes não obtiverem a nota mínima.

- A terceira fase é realizada na sede da coordenação estadual e participam os estudantes que na segunda fase atingiram nota mínima definida pela Comissão da OBF. A prova para os estudantes do ensino fundamental e dos dois primeiros anos do ensino médio é composta por uma prova experimental e por prova teórica. Para os alunos do 3 ano só há prova teórica. Os melhores alunos do 9o ano e 1응 ano do ensino médio participam de uma nova etapa que irá definir as equipes que representam o Brasil nas Olimpíadas Internacionais (IPHO e OIBF). Em

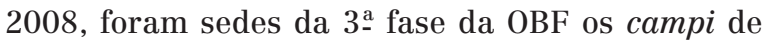
São Carlos, São Paulo e Lorena da Universidade de
São Paulo e o campus de Presidente Prudente da Universidade Estadual Paulista.

A prova experimental coloca os estudantes frente a problemas, que com raras exceções, são abordados no ensino médio e fundamental. É sabido que ensino experimental de física nesses níveis não é realizado na grande maioria das instituições de ensino do país.

Sabe-se que os alunos, tanto do ensino médio como do ensino fundamental, têm dificuldade na disciplina Física. Além das dificuldades conceituais, que é objeto da própria matéria, possuem muita dificuldade na resolução de problemas devido a falhas no processo de aprendizado, tanto conceitual como instrumental. Tais dificuldades e o não conhecimento da carreira científica levam o estudante a não se interessar por carreiras em ciências naturais.

Juntamente com as datas da 2ª e 3 a fases da Olimpíada, foram realizados no campus da USP em São Carlos atividades paralelas, tais como: palestras, visitas e mini-cursos para alunos e professores, abertas a todos os participantes. Estas atividades tinham como objetivo principal, além de abrir as portas da Universidade, mostrar um pouco da infraestrutura da Universidade e da pesquisa que é desenvolvida.

\section{RESULTADOS E DISCUSSÃO}

\section{PARTICIPAÇÃO DOS ESTUDANTES}

No ano de 2008 obteve-se um total de 773.379 participantes na primeira fase da Olimpíada Brasileira de Física em todo país, divididos entre alunos do 9ano do ensino fundamental (EF) e 1ㅇ , 2ㅇ e 3o anos do ensino médio (EM).

A tabela 1 mostra mais detalhadamente a divisão dos alunos participantes em todo o Brasil, comparativamente com o estado de São Paulo, nas 1a e 2a fases da Olimpíada Brasileira de Física do ano de 2008. Optou-se por não realizar uma análise da fase final da Olimpíada (3 a fase), por ser esta a fase onde são selecionados da ordem de 1.200 estudantes e ficam evidenciadas, principalmente, diferenças regionais e mesmo particularidades típicas de escolas que investem no treinamento de estudantes. 
TABELA 1

Resumo geral da participação na Olimpíada Brasileira de Física nas $1^{\mathrm{a}} \mathrm{e} 2^{\mathrm{a}}$ fases.

\begin{tabular}{|c|c|c|}
\hline \multicolumn{2}{|c|}{ PARTICIPANTES DA PRIMEIRA FASE } \\
\hline Série & Brasil & São Paulo \\
\hline $9^{\underline{0}}$ ano do EF & 147.955 & 16.930 \\
\hline $1^{\underline{0}}$ ano do EM & 243.545 & 20.744 \\
\hline $2^{\underline{0}}$ ano do EM & 202.570 & 18.649 \\
\hline $3^{\underline{0}}$ ano do EM & 179.309 & 15.943 \\
\hline Total & 773.379 & 72.266 \\
\hline
\end{tabular}

\begin{tabular}{|c|c|c|}
\hline \multicolumn{3}{|c|}{ PARTICIPANTES DA SEGUNDA FASE } \\
\hline Série & Brasil & São Paulo \\
\hline $9^{\underline{0}}$ ano do EF & 11.681 & 2.488 \\
\hline $1^{\underline{0}}$ ano do EM & 10.685 & 1.936 \\
\hline $2^{\underline{0}}$ ano do EM & 10.084 & 1.854 \\
\hline $3^{\underline{0}}$ ano do EM & 7.608 & 1.352 \\
\hline Total & 40.058 & 7.630 \\
\hline
\end{tabular}

Fica claro, através da tabela 1, que as tendências observadas no Brasil são praticamente as mesmas para o estado de São Paulo. Há uma queda expressiva na participação dos alunos à medida que estes avançam para o 3 ㅇ ano do ensino médio. Esta é uma tendência que já vem

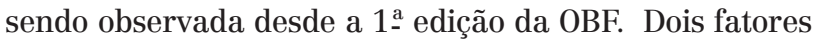
podem estar influenciando nesta queda:

i) 0 fato dos estudantes terem que se dedicar para 0 vestibular ao final do ciclo médio;

ii) 0 ensino de Física em nível médio não é atraente ao estudante, que acaba perdendo o interesse pela disciplina, já que quase na sua totalidade, o ensino é feito de maneira tradicional sem a realização de atividades experimentais. Até o 9o ano, Física é ministrada como parte de Ciências e integrada a esta.

Um terceiro ponto poderia ter sido colocado aqui, no que se refere à formação adequada dos professores de Física que ministram aulas no ensino médio e que acaba refletindo no seu interesse pela determinada matéria.

\section{DESEMPENHO DOS ESTUDANTES}

Dados do desempenho acadêmico dos estudantes foram analisados levando-se em consideração somente as notas da 2- fase do evento. Como descrito anteriormente, a prova da 2a fase é composta por oito questões discursivas com um total de 48 pontos. Verifica-se, através dos gráficos de 1 a 4 que, de forma geral, o desempenho de $70 \%$ dos estudantes fica abaixo de $10 \%$ do total geral de pontos. Resultados similares a este já foram obtidos em diferentes exames nacionais e internacionais.

\section{GRÁFICO 1}

Pontuação dos alunos do $9^{0}$ ano do EF na $2^{\text {a }}$ fase da OBF em 2008

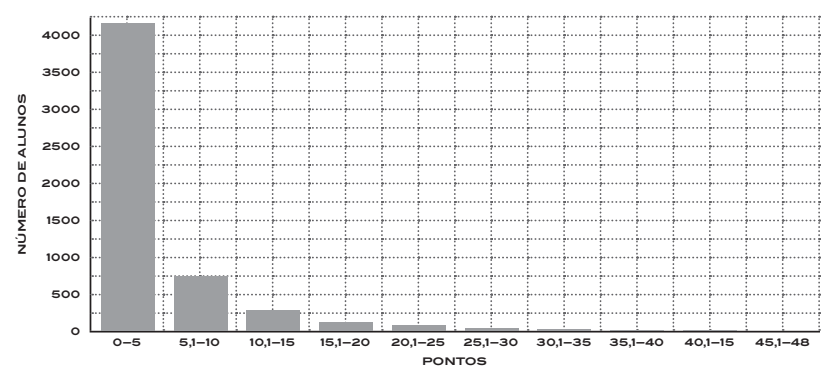

GRÁFICO 2

Pontuação dos alunos do $1^{0}$ ano do EM na $2^{a}$ fase da OBF em 2008

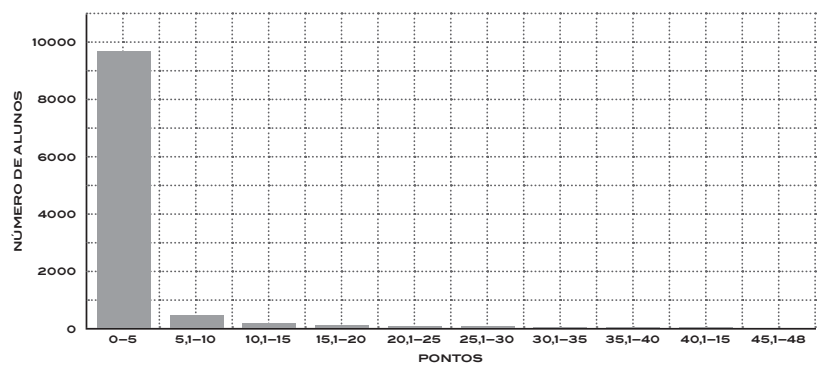

GRÁFICO 3

Pontuação dos alunos do $2^{\underline{o}}$ ano do EM na $2^{\underline{a}}$ fase da OBF em 2008

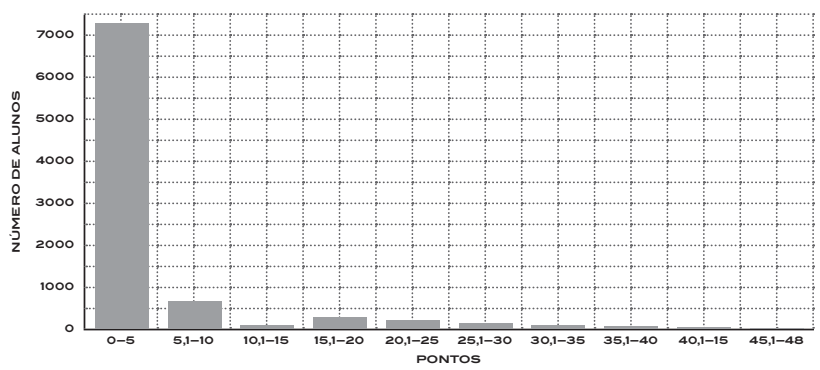

GRÁFICO 4

Pontuação dos alunos do $3^{0}$ ano do EM na $2^{a}$ fase da OBF em 2008

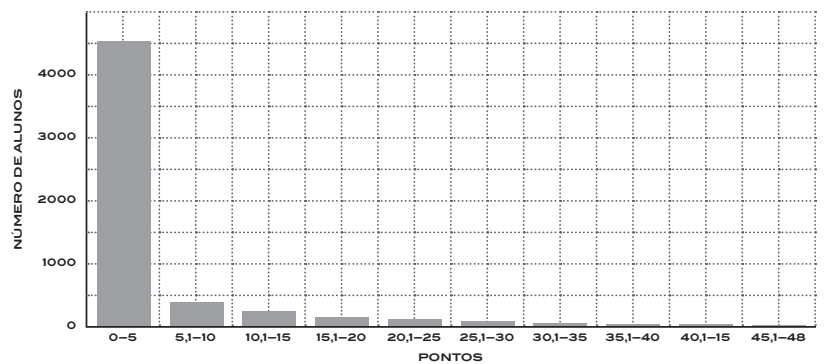


Uma leitura alternativa dos resultados acima mostra também que, além das deficiências apresentadas na formação, o estudo de ciências está cada vez mais fora dos objetivos imediatos dos jovens, e um dos fatores é que a sociedade como um todo tem pouca informação do que é feito em ciências no Brasil e qual o seu impacto na sociedade. Jovens talentosos optam por carreiras, cuja formação tem um impacto mais imediato no fator socioeconômico, em detrimento de carreiras científicas em que o período de formação é muito mais longo e a ascensão social lenta.

\section{LEVANTAMENTO DA PARTICIPAÇÃO DOS ALUNOS INGRESSANTES NOS CURSOS DE GRADUAÇÃO EM FÍSICA DA UNIVERSIDADE DE SÃO PAULO NO ANO 2009.}

Foram realizados dois levantamentos com os ingressantes nos cursos de Bacharelado e Licenciatura em Física nos Institutos de Física dos campi de São Paulo e São Carlos. Foi perguntado ao ingressante se ele havia participado da OBF e em caso afirmativo quantas vezes. Os resultados obtidos estão representados nos gráficos de 5 a 8.

\section{GRÁFICO 5}

Participação nas Olimpíadas de Física

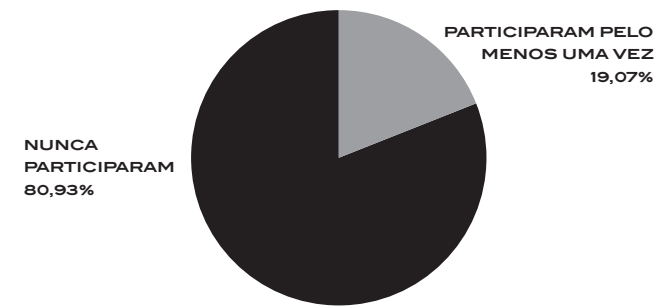

ALUNOS INGRESSANTES DE 2009 DO INSTITUTO DE FISICA DA USP SÃO PAULO

\section{GRÁFICO 6}

Alunos que participaram pelo menos uma vez das Olimpíadas de Física
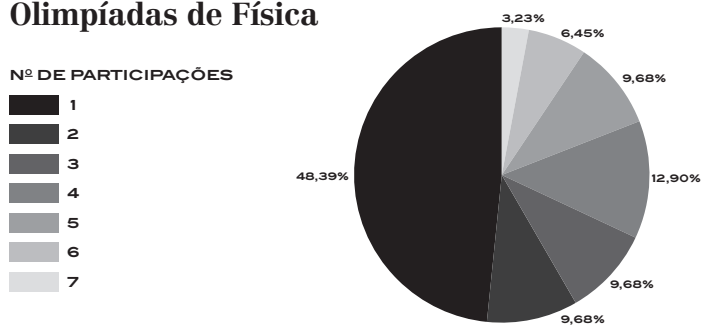

ALUNOS INGRESSANTES DE 2009 DO INSTITUTO DE FISICA DA USP SÃO PAULO
GRÁFICO 7

Participação nas Olimpíadas de Física

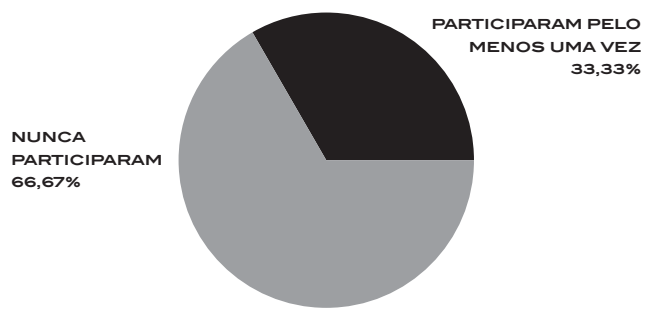

ALUNOS INGRESSANTES DE 2009 DO INSTITUTO DE FISICA DA USP SÃO CARLOS

\section{GRÁFICO 8}

Alunos que participaram pelo menos uma vez das

Olimpíadas de Física
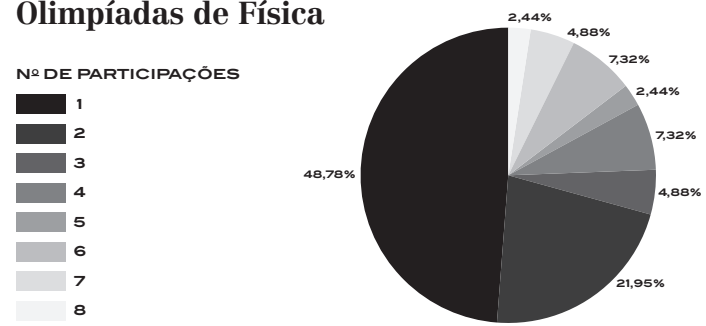

ALUNOS INGRESSANTES DE 2009 DO INSTITUTO DE FISICA DA USP SÃO CARLOS

Os resultados indicam que menos de $30 \%$ dos alunos ingressantes em 2009 nos cursos de Bacharelado e Licenciatura em Física da USP participaram da OBF pelo menos em uma oportunidade, sendo esta a grande maioria. É de se esperar que um aluno ingressante em Física tenha alguma afinidade prévia com esta disciplina, porém, a participação na OBF não mostra necessariamente esta. 0 fato do aluno não conhecer o evento é pouco provável, já que a divulgação é feita para atingir cerca de 95\% do estado de São Paulo.

\section{CONCLUSÃO}

Foram realizadas análises da participação e do desempenho dos estudantes que participaram da Olimpíada Brasileira de Física no ano de 2008. O desempenho observado é muito similar aos obtidos através de exames estaduais (SARESP), nacionais (Prova Brasil e ENEM) e internacionais (PISA). O que cabe aqui ressaltar é que a grande maioria dos estudantes que opta pela carreira de Física não participa da OBF. Acreditamos que o ingresso na carreira não deva estar relacionado com o desempenho, mas sim pela falta de conhecimento do que é feito na Universidade na área acadêmicocientífica em Física. 


\section{REFERÊNCIAS BIBLIOGRÁFICAS}

BELLIPANNI, L. J., LILLY, J. E. What have researchers been saying about science fairs? Science and Children 36:46-50. 1999.

GROTE, M. G. Science teacher educators' opinions about science projects and science fairs. Journal of Science Teacher Education 6:48-52. 1995.

HULER, S. Nurturing science' Young elite: Westinghouse. Talent Search. Science 5:20. 1991.

MANN, J. Z. Science day guide. Columbus: Ohio Academy of Science. 1984.

OLSON, L. The North Dakota science and engineering fair-Its history and a survey of participants. Unpublished manuscript. North Dakota State University, Fargo. 1985. 